\title{
A Guarda-Negra no Contexto Brasileiro de Final do Século XIX
}

\section{Maria Lúcia de Souza Rangel Ricci}

Quando nos propusemos a apresentar este trabalho ao I Simpósio Gaúcho sobre a Escravidão Negra, nosso interesse foi, entre outros, o de mostrar a contradição sempre observada com relação ao escravo, visto ao mesmo tempo como propriedade e como ser humano, o que sempre, ao longo do processo histórico brasileiro, gerou permanentes tensões, pois, ele representava tanto capital como trabalho, e, sua posse, configurava status ao seu senhor.

Convém lembrarmos que a elite brasileira, composta predominantemente por grandes proprietários e por comerciantes envolvidos na economia de exportação-importação, sempre esteve interessada em manter as estruturas tradicionais. Por isso, escolheram apenas os aspectos da ideologia liberal que melhor se adequavam à sua realidade e atendiam a seus interesses. Daí ser o seu liberalismo conservador, admitindo a escravidão, da mesma forma que, desde o início, conciliou a escravidão com o cristianismo.

Dessa forma, durante o final do século XIX, era ainda a sociedade brasileira dominada pelo sistema escravista, ou seja, por um sistema de produção social baseado no trabalho escravo. Os donos dos meios de produção (terras, matérias-primas, instrumentos de trabalho) eram, de igual modo, os donos da força de trabalho, constituída de trabalhadores mantidos sob estado de escravidão.

A existência dessa classe de escravos faz-nos supor claramente a da instituição jurídica da escravidão, apesar de que tal instituição, de per si, não fez dos escravos uma classe social, uma vez que seu status jurídico 
configurava uma condição estamental, advinda da propriedade do homem pelo homem, como bem móvel ${ }^{1}$.

Com isso, queremos dizer que as relaçöres entre escravos e seus senhores eram de cunho patriarcal - classe de escravos e classe de senhores-de-escravos - constituindo estes os focos do antagonismo social vigente. Daí, de igual forma, podermos ver em todos os movimentos em prol da libertação do negro a ação dos senhores-de-escravos, que não somente os dirigiu, como deles tirou proveito, apesar de existir no escravismo, desde sempre e em qualquer ocasião, um inesgotável protencial de rebeldia e rebelião.

Na marcha evolutiva do processo histórico brasileiro não há como separarmos a problemática da escravidão e suas implicações que culminaram com a campanha abolicionista e subseqüente abolição da escravidão, e o movimento republicano, donde emergiria a GuardaNegra, como uma amostragem, de um lado, da manipulação dos brancos sobre os negros e, de outro, a tênue porém marcante pretensão de alguns deles de tentarem se afirmar no mundo dos brancos.

A Guarda-Negra ou Guarda-Negra da Redentora, como foi chamada pela imprensa republicana da época, era composta pelos libertos agradecidos à Princesa Isabel pelo 13 de Maio. Organizada no Rio de Janeiro, a 28 de setembro de 1888 , foi inspirada e dirigida por José do Patrocínio, tendo como presidente honorário o Conselheiro João Alfredo de Oliveira, permanecendo em franca atividade até a Proclamação da República.

De início, funcionava modestamente na Rua da Carioca, $\mathrm{n}^{\circ} 77$ (antigo), local onde também funcionava uma Sociedade Recreativa denominada "Habitantes da Lua", contando então com 300 elementos aproximadamente.

A seguir, transferiu-se para a Rua Senhor dos Passos, $n^{\circ} 165$, local onde foi fundada a "Sociedade Beneficente Isabel, a Redentora", mais tarde instalada à Rua Larga de São Joaquim (hoje Marechal Floriano Peixoto).

Era chefiada, como o dissemos, por José do Patrocínio e na Cidade do Rio (jornal por ele dirigido), do dia 10 de julho de 1888 , lê-se que nasceu em casa de Emílio Rouède e, segundo informações de Rui Barbosa, no Diário de Notícias de 9 de maio de 1889, era presidida por Sampaio Viana. 
O número de alistados estava em torno de

"1500 a 1600 homens entre réus de polícia, capoeiras, navalhistas, malfeitores da pior casta, ao lado de outros que não devem inspirar senão piedade, pobres criaturas a quem nós abrimos o nosso coração, e que a venalidade maligna de traficantes famosos arrasta ao ódio contra os seus verdadeiros amigos, procurando trocar-lhes na mais estúpida vingança a gratidão devida aos lutadores desinteressados da causa abolicionista". ${ }^{2}$

Sua organização obedecia

"a compromissos solenes e graves rituais, o que the dava aparência de Maçonaria Negra; as sessões eram rigorosamente secretas, os iniciados contraíam juramentos sagrados, entre os quais o de guardar absoluto sigilo sobre as deliberações da casa. A violação dos segredos podia acarretar até a pena de morte [...]. Ao entrar para a milícia, cada um deles, de joelhos e com a mão sobre os Evangelhos, fazia o seguinte juramento:

Pelo sangue de minhas veias, pela felicidade dos meus filhos, pela honra de minha mãe e a pureza de minhas irmãs, e, sobretudo, por este Cristo, que tem séculos, juro defender o trono de Isabel, a Redentora. Em qualquer parte que os meus irmãos me encontrarem, digam apenas - Isabel, a Redentora - porque essas palavras obrigar-me-ão a esquecer a familia e tudo que me é caro".

Portanto, a Guarda-Negra surgiu, após a assinatura da Lei Área, chamando para o trono a simpatia dos conservadores, embora tivesse levantado contra ele, grosso modo, a cólera dos escravocratas e dos tidos como liberais. E a propaganda republicana aproveitara-se dessa oportunidade para afirmar-se junto à lavoura então sacrificada, aos fazendeiros, senhores de engenho, aos "patriarcas" rurais, enfim, aos quais a campanha libertadora tirara o braço escravo. Em pouco tempo os libertos, eternamente gratos à herdeira do trono, principalmente os da 
Capital do Império, vieram formar a coluna de defesa, engrossando fileiras da Guarda-Negra.

Se seu programa era defender a Princesa e, conseqüentemente, o trono, sua função constituíu-se, a cada momento, em espalhar o terror, perturbando as conferências republicanas, numa desatinada violência. $^{4}$

A tribuna popular, sem dúvida alguma, transformou o processo abolicionista num "espetáculo" coletivo, onde a oratória, mesmo que contundente, era primordial, espraiando-se do Parlamento para o teatro e deste para as ruas.

Como principal líder do movimento, José do Patrocínio provocou protestos, sendo-lhe condenado, principalmente, o radicalismo pela "aliança" feita com a herdeira do trono, bem assim, pelo fato de, num momento para outro, haver deixado de defender os ideais republicanos e tornar-se ardente defensor do $3^{\circ}$ Reinado.

A redação da Cidade do Rio, a partir de outubro de 1888, estava à disposição dos monarquistas, num combate aberto aos republicanos, principalmente àqueles que seguiam a orientação do grupo chamado revolucionário, liderado por Silva Jardim e Aníbal Falcão.

Em verdade, o ponto diametral entre Patrocínio e Silva Jardim era que o primeiro separava a questão política da social, enquanto o segundo tinha preocupação em analisar as condições econômicas de sua geração, passando desta análise à da psicologia social, para uma possível explicação de sua ideologia. Com isso, não estamos afirmando, naturalmente, que exista certa alma social, ou certo "espírito" popular coletivo que se desenvolva de acordo com leis próprias e que se manifeste na vida social, pois seria simplesmente puro misticismo; mas antes, uma análise da existência social para determinar as formas de consciências.

Por outro lado, devemos levar em conta que a História não pode limitar-se à anatomia da sociedade, mas deve apresentar todo o conjunto dos fenômenos, condicionados direta ou indiretamente pela economia social, inclusive o trabalho de imaginação.

Daí acreditarmos que, numa história das ideologias, possamos explicar, em grande parte, "o surgimento, a modificação e a destruição das associações de idéias sob a influência do surgimento, da modificação e da destruição de determinadas combinações de forças sociais", uma vez que a História é única e indivisível. ${ }^{5}$ 
Dia a dia, a ala republicana via fortalecer-se, não apenas pela doença do velho Imperador, como, basicamente, pela fraqueza da Princesa e ambição do esposo, sem falarmos da atitude do Ministério, que, tendo à frente "um ministro revoltantemente hiṕ́crita", procurava trair a propaganda republicana, tentando jogá-la contra os agricultores e subornando a Polícia para aliciar negros libertos que, sem terem ocupação, acabavam por ser "joguetes" nessas mãos. A tão decantada gratidão à Redentora pelo 13 de Maio era, pois, apenas um ardiloso artifício, que os corruptos e já poucos adeptos da Monarquia fizeram a esses negros. A propósito teria dito Silva Jardim, o líder republicano revolucionário:

“[...] A exploração do negro não cessou, eis a verdade, e quem a faz é o Ministério, é a Princesa Imperial, é o seu funesto marido e a dinastia. Para isso, põe em campo um ou outro negro ou mulato mais sagaz, mais intrigante, mais palrador. Os verdadeiros republicanos, os patriotas verdadeiros devem ter civismo para não odiar os pobres pretos quase irresponsáveis; mas também para não cair numa condescendência que seria covardia, não devem dar quartel, por menor que seja, aos pretos, verdadeiros ou falsificados, que, com mesquinhos interesses de branco, mas de branco servil, exploram seus pobres irmãos de raça: para esses todo o ressentimento, que é o mais digno, toda a punição, que é a mais merecida; esses é que devem pagar pelas feridas que recebemos, pelas mortes que lamentamos, e pelos ataques que ainda sofremos." 6

Em verdade, à medida em que os povos manipulados pela corrupção refletem a imagem na instituição que os cria, a nossa Monarquia era a mentira de todos os sistemas e, conseqüentemente, a negação de todos os elementos positivos de governo, advindo daí a falsidade de seus princípios, a fraqueza de suas crenças e o triste rebaixamento das consciências, ja que o caráter nacional, em todos os aspectos, estranhava o cunho vital das instituições que os dirigia.

Neste contexto, acreditamos, é que podemos entender como foi então organizada a Guarda-Negra e como conseguiu, ainda que por pouco tempo, sobreviver. 
Quer nos parecer, portanto, que, sentindo o Império Brasileiro "balançar-se" pela propaganda republicana, cujo ardor crescia a olhos vistos (tanto na tribuna, quanto na imprensa), os "fanáticos" do trono resolveram oferecer à Princesa tudo o que lhes restava, no sentido de assegurar-lhe força e prestígio e, em última instância, tentar garantir-lhe o trono. Surgindo, pois, a Guarda-Negra como um movimento de resistência em torno de S.A., numa especulação criminosa iniciada na Corte Imperial, com pouca ou quase nenhuma repercussão nas outras Províncias, encheu ela de sangue suas primeiras armas, na Capital do Império, a 30 de dezembro de 1888 , com total apoio da polícia:

"Esta instituição teve o seu berço na polícia, recebeu do Tesouro o enxoval, a benção do Presidente do Conselho e a santificação batismal da Regência. Nasceu adulta no mal e sequiosa de sangue, em que banhou as suas primeiras armas, a capital do Império, aos 30 de dezembro de 1888.

[...] A cumplicidade policial asssegura-lhe, por toda a parte a mais absoluta impunidade."

Referimo-nos à conferência republicana realizada por Silva Jardim a qual, atacada pelos "mazorqueiros" da Princesa, motivou luta com os populares que, pacificamente, assistiam à reunião, deixando como saldo dezenas de feridos e algumas mortes, segundo noticiário da imprensa da época. ${ }^{8}$

A triste atuação da Guarda-Negra na Capital prosseguia, sempre acobertada, tendo novamente ocorrido um outro incidente de graves conseqüências, no dia 21 de julho de 1889, na rua do Ouvidor, quando três marinheiros armados de navalhas e seguidos por um bando de capoeiras, armados de cacetes, atravessaram por duas vezes aquela rua, dando "Vivas à Monarquia":

"[...] Os soldados que rondavam a rua, conservaramse imóveis, vendo passar aquele sinistro grupo de desordeiros, que, ostensivamente e nas barbas da polícia provocavam um conflito. Se é um crime o grito sedicioso de - 'Viva a República' - , não menos criminoso é o ato praticado por esses desordeiros, com os quais poderia alguém dizer que está a polícia de acordo, à vista da indiferença com que ela os viu passar, agitando as suas navalhas e cacetes. 
[...] Esperamos do Sr. Dr. Chefe de Polícia as necessárias providências para que não se reproduza tão vergonhoso e aviltante espetáculo."

Por estar a Regência convencida de que governava um povo sem vontade, os meetings republicanos não cessavam de ocorrer, no intuito de convencer o povo de que não poderia dar-se por satisfeito apenas com a manifestação solene da vontade dominante, mas exigir que o poder se legitimasse pelo respeito ao bem público, já que a massa ou sofre sem protestos as maiores violências, ou, quando the respeitam a liberdade, atira-se-lhe aos mais censuráveis desmandos.

Não fora, em verdade, a Guarda-Negra uma instituição popular (visto que nem mesmo campo de ação teve em outras Províncias, pelo contrário, fora até repudiada pelos próprios negros), não passando de uma verdadeira "oligarquia armada". Entretanto, seus mentores procuravam demonstrar o seu aspecto positivo, quando se lê, através da imprensa da época, cá e lá, coisas do gênero:

"Em nome dos cidadãos que, levados pelo sentimento de gratidão e do patriotismo, hipotecaram sua vida e sua honra à Princesa Redentora, protesta contra as injúrias e atendos dos negros republicanos contra os homens de cor, e declaro que só por não ser o nosso propósito perturbar a ordem, nem provocar a anarquia, a Guarda-Negra não toma o desforço que ela devia tomar, porque tem força de sobra para desafrontar o seu nome $\mathrm{e}$ a sua raça.

A nossa calma é mais um sacrifício feito ao governo, que no dia 13 de maio fez uma pátria bastante grande para conter a nossa gratidão, e a torpeza dos assalariados do escravismo, mascarados em republicanos. Dia virá, porém, em que se mostrarão face a face os cidadãos que representam a honra de três séculos de trabalho martirizado, e o imperador dos exploradores que há trezentos anos nos incitam à afronta. - Clarindo de Almeida."10

E, no entanto, três meses antes desta declaração de Clarindo de Almeida, o Diário de Buenos Aires plublicava com o título "O Brasil arma-se", a seguinte notícia: 
"Uma carta do Rio de Janeiro, escrita por pessoa que nos merece todo o crédito, comunica-nos que o governo brasileiro comprou cinquenta mil espingardas do sistema Lebel, e que tendo-se procedido à experiência dessa arma no Campo Grande, reconheceu-se ela ser muito superior às outras até agora adotadas no exército imperial.

Como conseqüência dessas experiências a comissão de material de guerra aconselhou ao governo a aquisição de mais cem mil espingardas desse sistema, para substituírem as espingardas existentes nos arsenais do Império.

$\mathrm{Na}$ referida carta dizem-nos que estes armamentos respondem à eventualidade de uma comoção no Império, originada pelos trabalhos da propagandas republicana, que ultimamente tem assumido um caráter sério, pondo em perigo as instituições monárquicas.

Com o fim de combater o elemento radical, está se organizando um grande exército, composto dos libertos da lei de 13 de maio, exército que se intitula 'GuardaNegra da Redentora'.

Preparam-se, pois, os elementos para uma luta provável, que estalará quando deixar de existir o atual Imperador, e quando o substituir no trono a Princesa Isabel, a quem pretendem combater as forças republicanas, que também se estão organizando em todo 0 Império."11

No entanto, não encontramos nos Arquivos Policiais ou Judiciários da época nenhum documento que viesse a comprovar aberturas de inquéritos relativos a quaisquer dos conflitos atribuídos à Guarda-Negra, muito embora a imprensa do período nos diga ter sido instaurado inquérito e encaminhado ao Juiz de Direito do $7^{\circ}$ Distrito Criminal, tendo sido o mesmo aberto pela $3^{\text {a }}$ Delegacia de Polícia do Rio de Janeiro sobre o conflito de 30 de dezembro de 1888 , e tão somente sobre este, que parece ter sido o de maiores proporções. ${ }^{12}$ 
Essa política de reação contra os republicanos, organizada pelo Gabinete 10 de março, agindo conjuntamente com a Guarda-Negra, com a qual João Alfredo pretendia garantir o terceiro reinado, provocou protestos em várias localidades, sendo os mais significativos os ocorridos em Santos, Campinas, Casa Branca e Porto Alegre..$^{13}$

A nosso ver, pois, a rápida ascensão da idéia republicana no Brasil teve, neste último suporte da Monarquia, um dos seus porquê, uma vez que, se de um lado as condições econômico-sociais propiciaram a mudança para o trabalho livre e, em decorrência, o fim das formas tradicionais de vida que até então haviam sido os sustentáculos da Monarquia, por outro lado, a propaganda em si mesma contribuiu para desmoralizar mitos que a sociedade criara e que sabia não serem destruídos de imediato, mesmo porque o país continuaria a ser predominantemente agrário, possuindo tão somente prenúncios de transição para uma sociedade empresarial.

Sem dúvida alguma, poderíamos dizer ter sido a agitação provocada pela Guarda-Negra contra a propaganda republicana, na Capital do Império, a ação mais controvertida dos anos 1888/89, representando perfeitamente o caos econômico-sócio-político em que nos encontrávamos, promovendo uma ousada movimentação.

Os elementos mais extremados de toda essa agitação, que vinham desde a campanha abolicionista, se viram afastados do poder não demorando muito para que os grandes senhores rurais e seus prepostos (sobretudo os donos das lavouras cafeeiras), tivessem preponderância completa no recém-inaugurado regime, fazendo com que a burguesia nacional permanecesse sem oportunidades para desenvolver-se ou impor-se frente às transformações sócio-políticas brasileiras.

Por sua feita, o negro ficou sem condições de adaptar-se à nova sistemática do trabalho que lhe fora imposta à economia urbano-comercial, sentindo-se espoliado, em súbita competição com o branco, relegado a uma condição de marginalidade, aqui entendida como situação social independentemente da teoria da personalidade marginal (isto é: todo elemento marginal existe na sociedade, porque existe essa sociedade).

E o envolvimento do negro, basicamente o do Rio de Janeiro, a favor de uma decadente Monarquia e contrário, pelo menos na aparência, aos ideais do republicanismo, teria residido, a nosso ver, em decorrência da falsidade da chamada tolerâmia racial havida no Brasil, 
onde a mobilidade vertical existente dentro do sistema social vigente não se organizou para os negros como um processo histórico e uma realidade coletiva, em nada repercutindo na alteração dos estereótipos negativos, ou mesmo nos padrões que regiam as relações raciais. Teria sido, pois, tal problemática de caráter estrutural e, por isso mesmo, fácil de ser conduzida em nome da ascensâo social e da profunda gratidão à Redentora, fazendo com que, uma vez mais, o negro ficasse à mercê daquele que sempre o oprimiu.

Com a Guarda-Negra, pois, o sistema institucionalizara a violência, exercida às claras, objetivando a dominação do negro frente ao controle direto do seu comportamento. A elite branca já possuía em sua própria sociedade elementos suficientes para forjar sua ideologia racial, uma vez que, ao longo de sua trajetória, aprendera a ver os negros como inferiores, abrindo poucas exceções para alguns "indivíduos" negros ou mulatos. $\mathrm{E}$, foi tão somente a partir da $3^{\mathrm{a}}$ década do século $\mathrm{XX}$, principalmente com o incremento da urbanização, do crescimento da população e da relativa distribuição da riqueza, que a situação foi se tornando mais difícil para a elite tradicional manter sua antiga posição, não apenas pelas divisões em seu interior, como também pela oposição de setores progressistas aos grupos tradicionais. A Revolução de 30 poria fim à hegemonia política das oligarquias tradicionais, sem contudo alterar consubstancialmente a situação do negro; antes, não chegou a integrá-lo no contexto, o que permitiu, de certa forma, a proliferação do racismo e a dificuldade da própria organização do movimento negro.

\section{Notas}

1. Utilizamos aqui o conceito de classe no seu sentido amplo. Ver sobre o assunto: "La Conciencia de clase en la Historia", E.J. Hobsbawm, in MÉSZAROS, Istvan. Aspectos de la Historia y la Conciencia de Clase. México, 1973.

2. BUARQUE, Felício. Origens Republicanas. Estudos de Gênese Política. São Paulo, Edaglit, 1962. p.83.

3. ORICO, Osvaldo. O Tigre da Abolição. Ediçăo Comemorativa do Centenário de José do Patrocínio, s.l.p., MCMLIII. p.203.

4. Sobre o assunto consultar: ORICO, Osvaldo. Op. cit, p.205.

5. PLEKHÂNOV, G. A Concepção Materialista da História. 2.ed. Rio de Janeiro, Editorial Vitória, 1963. p.67.

6. JARDIM, Antônio da Silva., Carta Política ao País e ao Partido Republicano. Rio de Janeiro, Mont-Alverne, 1889. p.13/14.

7. Sobre o assunto ver: BARBOSA, Rui. A Queda do Império. Rio de Janeiro, Castilho, 1921. (Coleção de artigos publicados no Diário de Notícias, in "Campanhas jornalísticas", abril e maio de 1889.) 
8. "Noticiário". Diário Popular, São Paulo, dezembro 31, 1889; O Paiz, Rio de Janeiro, janeiro 10,1889 , que publica integralmente o depoimento prestado por Silva Jardim frente à polícia da Corte, a propósito desses acontecimentos ocorridos no dia $30 \mathrm{de}$ dezembro.

9. "Viva a Monarquia". A Gazeta de Notícias, Rio de Janeiro, ano XV, $\mathrm{n}^{2} 203$, julho 22, 1889. p.1.

10. "Guarda-Negra". Gazeta de Notícias, Rio de Janeiro, ano XIV, $\mathrm{n}^{2} 364$, dezembro 30 , 1888. p.2.

11. "O Brasil Arma-se". Gazeta de Notícias. Rio de Janeiro, ano XIV, n² 271, setembro 28, 1888. p.1.

12. Ver sobre o assunto: "Propaganda Republicana. A Responsabilidade do conflito". Gazeta de Notícias, Rio de Janeiro, ano XV, n² 25, janeiro 25, 1889. p.2, e "Secção Livre - O conflito do dia 30 - Ao Público". O Paiz, Rio de Janeiro, ano VI, no 1.582 , fevereiro 5,1889 . p.2.

13. "Propaganda Republicana. A Guarda Cívica". Gazeta de Notícias, Rio de Janeiro, ano $\mathrm{XV}, \mathrm{n}^{2}$ 33, fevereiro 2, 1889. p.2; "Partido Republicano". O Paiz, Rio de Janeiro, ano VI, $n^{2} 1.610$, março 5, 1889. p.3; e "Notícias. A Guarda-Negra". A Província de São Paulo, São Paulo, ano XV, n 4.158, fevereiro 10, 1889. p.2. 